\title{
Review Article \\ Cancer Stem Cell Markers in Head and Neck Squamous Cell Carcinoma
}

\author{
Aidan G. Major, ${ }^{1,2}$ Luke P. Pitty, ${ }^{1,2}$ and Camile S. Farah ${ }^{1,2}$ \\ ${ }^{1}$ School of Dentistry, The University of Queensland, 200 Turbot Street, Brisbane, QLD 4000, Australia
}

${ }^{2}$ The University of Queensland Centre for Clinical Research, Herston, QLD 4029, Australia

Correspondence should be addressed to Camile S.Farah; c.farah@uq.edu.au

Received 28 November 2012; Accepted 23 January 2013

Academic Editor: Rihab Nasr

Copyright (C) 2013 Aidan G. Major et al. This is an open access article distributed under the Creative Commons Attribution License, which permits unrestricted use, distribution, and reproduction in any medium, provided the original work is properly cited.

\begin{abstract}
Head and neck squamous cell carcinoma (HNSCC) is one of the world's top ten most common cancers. Current survival rates are poor with only $50 \%$ of patients expected to survive five years after diagnosis. The poor survival rate of HNSCC is partly attributable to the tendency for diagnosis at the late stage of the disease. One of the reasons for treatment failure is thought to be related to the presence of a subpopulation of cells within the tumour called cancer stem cells (CSCs). CSCs display stem cell-like characteristics that impart resistance to conventional treatment modalities and promote tumour initiation, progression, and metastasis. Specific markers for this population have been investigated in the hope of developing a deeper understanding of their role in the pathogenesis of HNSCC and elucidating novel therapeutic strategies.
\end{abstract}

\section{Introduction}

HNSCC is the eighth and 13th most common malignancy in the world for males and females, respectively, with the majority of malignancies of the upper aerodigestive tract being oral squamous cell carcinomas [1-5]. Despite advances in the understanding and treatment of HNSCC, survival rates have not significantly improved for over 30 years, with the five-year survival rate after diagnosis remaining at $15-50 \%$ [1, 6-8]. Current treatments for HNSCC can be traumatic, painful, and disfiguring, drastically affecting quality of life [9-11]. At present, management of HNSCC includes surgical resection and/or combination chemotherapy and radiation therapy $[2,4,6]$. Despite these treatments, the prognosis of HNSCC remains poor due to late stage diagnosis, high rates of primary-site recurrence, and common metastases to locoregional lymph nodes $[1,3,4,6,12]$. A desire to improve diagnostic capabilities and treatment efficacy has led to a need for a better understanding of the pathogenesis and characteristics of HNSCC.

Observations of the initiation, progression, and recurrence of cancer have led to two main hypotheses. The stochastic model suggests that there is an accumulation of numerous and varied individual mutations and microenvironmental signals that provide a selective advantage to certain tumour cells however all tumour cells have the ability to propagate the tumour $[13,14]$. The probability of the necessary mutations in any given individual cell is very low $[13,15]$. Conversely, the cancer stem cell hypothesis proposes a hierarchical model of tumour initiation and progression which suggests that only a specific subpopulation of self-sustaining cancer cells have the exclusive ability to maintain the tumour $[7,13,16,17]$. Recent research suggests that part of the mechanisms of recurrence and metastases in some cancers may be due to cancer stem cells (CSCs) $[7,15,16,18]$. There is mounting evidence for the presence of CSCs in HNSCC with dramatic implications for diagnosis, prognosis, and treatment.

\section{The CSC Concept}

CSCs are defined as a small subpopulation of cancer cells that constitute a pool of self-sustaining cells with the exclusive ability to cause the heterogeneous lineages of cancer cells that comprise the tumour $[7,17,19]$. There are three main characteristics of CSCs. Initially, the cell must show potent tumour initiation in that it can regenerate the tumour which it was derived from a limited number of cells. In addition, 
the cells should demonstrate self-renewal in vivo, which is practically observed via regrowth of phenotypically indistinguishable and heterogeneous tumours following serial transplantation of reisolated CSCs in secondary and tertiary recipients. Finally, the cells must show a differentiation capacity, allowing them to give rise to a heterogeneous progeny, which represents a phenocopy of the original tumour $[15,17]$.

Although some have argued that CSCs may arise not only from normal stem cells by mutation of genes that render the cells cancerous but also from progenitor cells, it is hypothesised that these cells experience further genetic alterations and therefore become dedifferentiated and acquire CSC features $[17,18]$. The term cancer stem cells refers to the functional properties of the cells and not their origin $[19,20]$.

In 1978, Julius Cohnheim proposed the concept that tumours were the result of residual embryonic cells [21]. Almost two decades later, a $\mathrm{CD} 34^{+} \mathrm{CD} 38^{-}$subpopulation of cells were isolated in acute myeloid leukaemia which, when transplanted into NOD/SCID mice, were capable of initiating acute myeloid leukaemia [22]. Then in 2003, the first solid tumour CSCs were isolated from breast cancer using a $\mathrm{CD} 44^{+} \mathrm{CD} 24^{-} \mathrm{Lin}^{-}$marker phenotype [23]. To date, CSCs have been isolated in hematopoietic malignancies and several solid tumours including breast [24], brain [25], prostate [26, 27], lung [28], colon [29], pancreas [30], liver [31], melanoma [32], skin, head, and neck [16]. The identification of CSCs in various malignancies has also revealed that CSCs are largely tissue specific and that a universal CSC marker is unlikely $[17,33,34]$.

In addition to the abilities of self-renewal, differentiation, and regeneration, CSCs possess significant resistance to current treatment modalities such as chemotherapy and radiotherapy [35-44]. This characteristic of CSCs has significant treatment implications as current modalities allow resistant CSCs to reinitiate the tumour [45]. Current methods of reporting treatment success are based on measuring the overall reduction in the size and number of cells remaining after treatment $[21,46]$. This does not take into account the proportion of cells within that population that are CSCs and therefore have the ability to orchestrate a relapse $[21,46]$. The CSC theory demands a shift in measurement of treatment success $[21,46,47]$. Furthermore, it has become apparent that CSCs facilitate the metastatic characteristics of tumours [42, 48-54]. CSCs are capable of epithelial mesenchymal transition (EMT), which is a key step in wound healing and embryogenesis $[33,50,55]$. The genetic programs involved in EMT are activated in CSCs and involve breakdown of cell contacts and migration allowing the tumour cells to metastasize $[33,50]$. The identification of this process and the biomarkers involved may serve as useful prognostic tools and therapeutic targets [50].

The isolation of CSCs via flow cytometry according to specific cell biomarkers is a widely used approach [56]. Dye exclusion assays have also been used to isolate side populations from tumour tissues. Finally, CSCs can be isolated via anchorage-independent culture assay. The identified cell must be able to "recapitulate the generation of a continuously growing tumor" [19]. As a result, the gold standard established for the qualification of this definition is a serial animal transplantation model [19]. Respect for the effect of the transplant and assay environments on the putative CSCs must be taken into consideration when assessing whether the cell meets the criteria of a CSC [19]. Studies have also been completed analysing the expression of "stemness" genes in suspected CSC populations using reverse transcriptase polymerase chain reaction (RT-PCR) techniques [19]. There is currently no ideal assay for the identification of CSCs however valuable insight and evidence of the role of CSCs in tumour initiation and progression are occurring.

This paper aims to provide a critical review of the putative HNSCC CSCs currently being investigated and provide evidence for potential novel markers.

\section{CSC Biomarkers in HNSCC}

3.1. CD44. CD44 is a large cell surface glycoprotein that is involved in cell adhesion and migration and is one of the most well-known markers for CSCs [13]. CD44 is thought to be involved in tumour progression and metastasis through its role as a regulator of growth, survival, differentiation, and migration [52, 57]. Through its interactions with hyaluronic acid (HA), chondroitin sulphate, and heparan sulphate, CD44 is able to bind growth factors and metalloproteinase MMP9, resulting in inhibition of apoptosis, collagen degradation, invasion, and neorovascularization [58-63]. CD44 has been identified as a biomarker in breast, CNS, colon, prostate, and pancreas tumours $[16,25,26,64-67]$. Prince et al. used an immunodeficient mouse model to demonstrate that a subpopulation of cells derived from primary, unmanipulated HNSCC were able to meet two defining properties for a CSC: self-renewal and differentiation [16]. They were able to obtain new tumours from $5 \times 10^{3} \mathrm{CD} 44^{+}$cells derived from earlier passaged xenograft tumours, whereas $5 \times 10^{5} \mathrm{CD} 44^{-}$ cells failed to form tumours. Despite demonstrating that the tumourigenic potential lay within the $\mathrm{CD} 44^{+}$cell population, the large number of cells needed to initiate tumours (5000) indicated that the $\mathrm{CD} 44^{+}$subpopulation was not a pure CSC population $[16,23]$. Since then, several studies have demonstrated that $\mathrm{CD} 44^{+}$subpopulations, emanating from both primary tissues and cell lines, exhibit a higher potential for proliferation, differentiation, migration, invasion, tumour sphere formation, and resistance to chemotherapeutics [3, $5,12,16,68-74]$. It was also observed that CD44 isoforms v3, v6, and v10 were significantly associated with advanced primary tumour stage, metastasis, treatment failure, and reduced disease-free survival, indicating that $\mathrm{CD} 44$ is a useful marker for HNSCC progression and a possible target for therapy [75]. CD44 was used to assess the metastatic potential of HNSCC CSCs in both an in vitro and in vivo study showing no difference in metastatic ability in vitro but found $\mathrm{CD} 44^{\text {high }}$ cells resulted in lung lesions, when injected in tails of NOD/SCID mice about $50 \%$ of the time compared to $0 \%$ for $\mathrm{CD} 44^{\text {low }}$ cells [51]. Most recently, the frequency of $\mathrm{CD} 44^{+}$cells correlated with poor prognosis, more aggressive tumours, and higher rates of recurrence following radiotherapy [72]. These results further support the CSC theory and demonstrate that the CSC burden and not the overall burden 
is an important prognostic factor. The use of CD44 expression as a prognostic indicator has also been suggested, with several studies reporting a statistically significant association between CD44 expression and decreased 5-year survival [76, 77].

Conversely, the use of CD44 as a marker has been questioned due to research suggesting that it is abundantly expressed in head and neck squamous cell carcinomas and that it is equally expressed in normal head and neck epithelium $[50,78]$. A study conducted by Lim et al. (2011) also puts the use of CD44 as a CSC marker into question as they found that both $\mathrm{CD} 44^{+}$and $\mathrm{CD} 44^{-}$cells derived from squamospheres could regenerate these spheres from single cell suspensions [79].

3.2. ALDH. The aldehyde dehydrogenase family, of which ALDH1 is a member, is a family of cytosolic isoenzymes, which are highly expressed in many stem and progenitor cells $[71,80]$. Their known functions include the conversion of retinol to retinoic acid in early stem cell differentiation and catalysing the oxidation of toxic intracellular aldehyde metabolites into carboxylic acid [71, 80]. As with CD44, the lead for investigating ALDH as a marker for CSCs in HNSCC followed identification in other solid malignancies such as breast, colon, liver, and lung tumours [81-84]. ALDH1 ${ }^{+}$cells from head and neck squamous cell carcinoma cell lines and primary tissue samples have demonstrated spheroid formation, tumour formation, increased invasion capabilities, selfrenewal abilities, and resistance to chemotherapeutics [42, $50,71,80,85]$. ALDH1 expression has a positive correlation to staging of HNSCC and a negative correlation to patient outcome [71]. As few as $500 \mathrm{ALDH1}^{+}$cells were able to generate tumours using an SCID mouse model, and $\mathrm{ALDH}^{+}$ cells showed superior ability to form spheroid colonies, higher invasion capacity, and increased radiation survival $[71,80]$. There is a significant overlap in the ALDH and CD44 populations with $50.6 \%-74.4 \%$ of $\mathrm{ALDH1}^{+}$cells expressing CD44 and only $9.8 \%-23.6 \%$ of CD44 cells demonstrating high ALDH activity indicating that ALDH1 may be a more specific marker of CSCs in HNSCC [80]. Chen et al. further characterised the gene expression of $\mathrm{ALDH}^{+}$cells and found the expression profile to be more similar to that of epithelial stem cells (ESCs) than ALDH1 ${ }^{-}$cells, detecting over expression of stemness-related genes and a reduction in cell-to-cell contact $[50,85]$. As few as $20 \mathrm{ALDH}^{+} / \mathrm{CD} 44^{+} / \mathrm{CD} 24^{-/ \text {low }}$ cells from breast cancer have been shown to initiate tumour growth; however such a small subpopulation capable of tumour growth is yet to be investigated in HNSCC [81]. Recent experiments have however found that low expression of ALDH is linked to poor prognosis rather than overexpression [86].

3.3. CD133. This pentaspan transmembrane glycoprotein has been identified as a putative CSC marker in brain, prostate, lung, skin, liver, and colorectal cancers [87]. A number of studies have suggested that $\mathrm{CD}_{133^{+}}$cells isolated from head and neck squamous cell carcinoma cell lines display increased clonogenicity, an EMT phenotype, tumour sphere formation, self-renewal, proliferation, multilinear differentiation, and tumorigenicity $[69,88-90]$. Zhang et al. was able to isolate a $\mathrm{CD}_{133^{+}}$population of cells expressing higher levels of stemness genes, successful spheroid formation, heterogeneous tumour formation, and increased clonogenicity from OSCC cell lines $(\sim 1-2 \%)$ and also from human OSCC specimens ( 1$3 \%)$ [88]. Recent studies have found a correlation between expression of CD133 and stage of carcinogenesis with stage III and IV tumours displaying higher levels than stages I and II. The role of $\mathrm{CD}_{133^{+}}$as a CSC marker in HNSCC still requires further investigation, and it is worth noting considerable discrepancy in CSC characteristics among other cancers in which CD133 is reported as a CSC marker with some studies showing similar tumour-initiating behaviour between $\mathrm{CD}_{133^{+}}$and $\mathrm{CD}_{133^{-}}$populations alike [91-94].

3.4. c-Met. c-Met, a tyrosine kinase receptor for hepatocyte growth factor (HGF), is associated with metastasis and tumour invasion, decreased survival, and was recently investigated as a marker for CSCs in HNSCC $[54,95,96]$. Sun

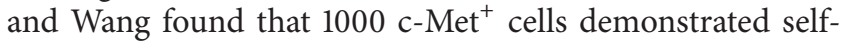
renewal and were able to generate heterogeneous tumours

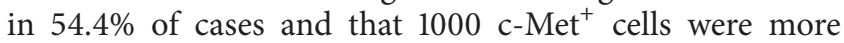
tumourigenic than $1000 \mathrm{CD} 44^{+}$, which were only able to generate tumours in $33.3 \%$ of cases [54]. When both markers were used the success rate of the c-Met ${ }^{+} / \mathrm{CD} 44^{+}$combination yielded tumours in $80 \%$ of cases injected with 1000 cells compared to the success rate of $\mathrm{ALDH} 1^{\text {high }}$ cells, which yielded tumours in $66.6 \%$ of cases [54]. Unfortunately, not all HNSCC specimens were used in both transplantation phenotypes; however the specimens displayed an increase in tumour formation from $66.6 \%$ in the ALDH1 ${ }^{\text {high }}$ to $75 \%$ in the

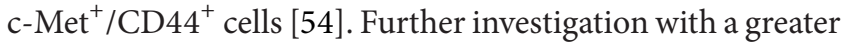
number of samples and a comparison of $\mathrm{c}-\mathrm{Met}^{+} / \mathrm{CD} 44^{+}$ to $\mathrm{c}-\mathrm{Met}^{+} / \mathrm{CD} 44^{+} / \mathrm{ALDH} 1^{\text {high }}$ tumourigenicity is yet to be completed.

3.5. Side Populations and Drug Efflux Transporters. Subpopulations of Hoechst 33342 dye-resistant cells termed "side population" (SP) cells have shown to express stem cell qualities when isolated from cancer samples [3]. It is thought that the dye is pumped out by the ATP-binding cassette (ABC) family of proteins including MDR1, MRP1, ABCB5, and ABCG2 [97]. SP cells from OSCC have shown to be more tumourigenic, chemoresistant and have demonstrated selfrenewal in vivo [3]. Usually, Hoechst 33342 dye is effluxed by ABCG2 so it is considered to be a CSC marker in OSCC [3]. It has also been suggested that the presence of ABCG2 is strongly predictive of cancerous transformation of oral leukoplakia [98]. Similarly, high ABCB5 expression has shown to be associated with OSCC progression and recurrence making it a possible prognostic factor [99].

\section{Stemness Markers}

The use of CSC-isolating techniques such as sphere formation, side population, and flow cytometry has accommodated 
the profiling of these subpopulations for known stemnessrelated genes $[3,8,42,50,85,88]$. These genes include transcription factors, that maintain pluripotency and selfrenewal, genes related to EMT, quiescence, and components such as myofibroblasts that are engaged in maintaining the CSC stemness and niche.

It has been suggested that embryological stem cells have a core regulatory network involving three master regulators for self-renewal and maintenance of the undifferentiated state $[100,101]$. These regulators are the POU domain transcription factor Oct-4 [102-104], the homeodomain transcription factor Nanog $[105,106]$, and the high mobility group protein Sox-2 [107]. Additionally, Oct-4 and Nanog have been suggested as two of the four major factors that allow reprogramming of adult cells into germ-line competent, induced pluripotent cells [108-110]. Oct-4 plays a critical role in the development and self-renewal of embryonic stem cells and has been linked to oncogenic processes [8, 111-113], Nanog maintains pluripotency of embryonic stem cells and functionally blocks differentiation $[105,114]$. Chen et al. found that the epithelial stem cell gene Oct- 4 was upregulated in ALDH1+ HNSCC cells and that Oct3/4, Sox 2 and Nanog were all up regulated in a population of spheroid-derived cells from HNSCC $[50,85]$. Similarly, Siu et al. demonstrated that Oct-3/4 along with TRA1-60, a tumour rejection antigen that is expressed on embryonic stem cells but vanishes upon differentiation, were detectable in the most invasive of six oral cancer cell lines suggesting that Oct-3/4 and TRA160 are markers indicating invasiveness [115]. Chiou et al. postulated that Oct-4 and Nanog play a role in tumour transformation, tumourgenicity, and metastasis finding an increased expression of these genes in a CSC-enriched subpopulation derived from sphere formation colonies from OSCC [8]. Furthermore, it was demonstrated that patients displaying a triple-positive expression of Oct-4, Nanog, and CD133 had the worst survival prognosis of all OSCC patients [8]. Additionally, it has been suggested that Oct- 4 and Nanog overexpression is positively correlated with chemoresistance and stage while negatively correlated with differentiation status $[8,116]$. This has led some to suggest that Oct- 4 may be a useful prognostic indicator for hypopharyngeal squamous cell carcinoma [117].

SOX2 has shown to have increased expression (including copy number increase and amplification) in tumours of squamous lineage. It has been shown that SOX2 is amplified specifically in squamous cell carcinomas of the lung and esophagus but not in lung or esophageal adenocarcinomas [118]. This is thought to demonstrate SOX2 as a lineagespecific stem cell marker, and, in the context of its usefulness in identification of stem cells in HNSCC, this would be specifically related to the squamous lineage. Interestingly, however, a recent study found no change in expression of Oct-4, Nanog, or Sox 2 between cell lines of varying degrees of disease from normal oral tissue to oral SCC [119].

EMT is an essential step in embryogenesis and wound healing allowing epithelial cells to breakdown cell-to-cell and cell-to-matrix connections facilitating the migration of these cells to other sites in the body and appears to be activated during epithelial cancers, facilitating migration and metastasis $[49,50,55,120,121]$. In order to metastasize, cancer cells undergo EMT and as such acquire the stem cell phenotype associated with this transformation [122]. The transcription factors Snail and Twist play key roles in the induction and coordination of EMT [123]. ALDH1+ HNSCC CSCs were found to have an increased expression of the Snail gene which correlated with metastasis, local recurrence, prognosis, proinflammatory mediators, and the aggressiveness of tumours [71, 85, 124-127]. Increased expression of Twist was found in CD44+ and ALDH+ HNSCC CSC-like cells and showed a loss of E-cadherin mediated cell-to-cell contacts, display of mesenchymal markers, and increased motility $[70,126]$. The Wnt-signalling pathway is known to modulate neural crest development [128]. Abnormal Wnt signalling has already been demonstrated in HNSCC and may potentially induce Twist expression in carcinoma cells $[126,129,130]$. The EMT transcription factors ZEB1/2 have shown to be overexpressed in CSC-like cells in HNSCC and are linked to decreased survival rates, increased sphere formation, CD44+ cells, tumour growth, and metastasis [131].

These stem cell-related genes and the abnormal activation of the Wnt-signalling pathway in HNSCC provide valuable insight into the characteristics of CSCs and their role in metastasis, self-renewal, and maintaining pluripotency. Just how these genes relate to other CSC markers in head and neck cancers is still largely unknown; however these stemness genes may help to differentiate CSCs from normal tissue cells displaying similar markers.

4.1. Bmi-1. Bmi-1 is considered to be a stemness-related gene maintaining the self-renewal capacity of stem cells through regulating chromatin structure $[7,42,85]$. Although Bmi1 has not been identified as a marker for HNSCC CSCs in its own right, its tumourigenic capacities and increased levels in $\mathrm{ALDH1}^{+}$subpopulations have made it a target of examination and is considered a critical factor in predicting disease progression and clinical outcomes [42]. Bmi-1 is an essential constituent of the polycomb repressive complex 1 , a key epigenetic regulator that regulates a number of biological processes, including $\mathrm{X}$ chromosome inactivation, carcinogenesis, and stem cell renewal $[132,133]$. Through chromatin and histone modification Bmi-1 is believed to promote cellular proliferation $[132,133]$. This is achieved by repressing the expression of the ink4a locus, which plays a pivotal role in the onset of cellular senescence. It also influences central tumour suppressors $\mathrm{Rb}$ and $\mathrm{p} 53[132,133]$. A moderate body of evidence has suggested that CSC-like subpopulations isolated from HNSCC cell lines and biopsies overexpress this protein $[3,16,42,85,130,134-136]$. Insight into the role of Bmi-1 in such populations was provided by Chen et al. (2010), who used a lentiviral vector expressing sh-Bmi-1 to knock down Bmi-1 expression in an ALDH1 ${ }^{+}$ HNSCC subpopulation [85]. Bmi-1 knock down resulted in significant suppression of self-renewal and radiochemoresistance both in vitro and in vivo [85]. Bmi-1 overexpression in a HNSCC-derived $\mathrm{ALDH1}^{-} \mathrm{CD} 44^{-}$subpopulation resulted 
in a restoration of stemness properties and self-renewal abilities and was sufficient for the promotion of CSC stemness [137]. Manufactured Bmi-1 overexpression in an $\mathrm{ALDH}^{+}$subpopulation of HNSCC resulted in increased soft agar colony formation, migration, invasion, and elevated expression of Snail, ALDH, and embryonic stem cell transcriptomes [42]. In addition, overexpression of Bmi-1 increases tumour formation, ionizing radiation resistance, local invasion, distant metastasis to the lungs, and tumour size in vivo $[42,138]$. IHC analyses of HNSCC biopsies from 93 patients found that coexpression of Bmi-1, Snail and ALDH1 correlated with poor overall survival and was associated with high-grade, poorly differentiated HNSCC [42]. Bmi-1 may also play a role in the progression of potentially malignant lesions as it has been observed that Bmi-1 overexpression occurs in mild, moderate, and severe epithelial dysplasia [133]. It has also been suggested that the presence of Bmi-1 is strongly predictive of cancerous transformation of oral leukoplakic lesions [98].

Somewhat opposed to the above evidence, a study examining the correlation between Bmi-1 and prognosis of squamous cell carcinoma of the tongue has suggested that negative Bmi-1 immunoexpression, and not overexpression, was associated with a high risk of recurrence [132]. The divergence of tongue SCC from the above results could possibly relate to the varying pathophysiologies and aetiologies of HNSCC [42]. Some suggest that tongue cancer has a closer relationship with human papilloma virus as opposed to other aetiological agents such as tobacco and alcohol associated with other HNSCC $[139,140]$.

Despite the contradictions, it would appear that Bmi-1 plays a substantial role in the tumourigenesis of HNSCC. Future research is required to determine whether it is suitable as a CSC marker and the precise role it plays in the pathogenesis of HNSCC.

4.2. Lgr5. The $\mathrm{Wnt} / \beta$-catenin-signalling pathway regulates proliferation and is central to embryonic development and organogenesis in several species. The main role of this pathway is to phosphorylate the $\beta$-catenin protein, leading to its protaesomal degradation. This is required as $\beta$ catenin interacts with DNA-binding protein transcription factor 4 leading to the activation of several genes [141, 142]. Abnormalities in this pathway, leading to cytoplasmic $\beta$ catenin accumulation, have been suggested to be associated with tumourigenesis in several tissues of epithelial origin including intestinal, colonic [142], esophageal [143], ovarian [144], and hepatic tissues [145]. Furthermore, it has been suggested that abnormal activation of this pathway is associated with head and neck carcinoma [130]. LGR5 (also known as GPR49) is a seven-transmembrane-domain receptor protein, and similar to EMT, is targeted by the Wnt-signalling pathway [146]. LGR5 marks rapidly dividing cells in hair follicles, colon, and the small intestine [146]. During embryogenesis, LGR5 has a broad and complex expression, and it has been suggested to be a marker for adult stem cells of the intestine, stomach, and hair follicle $[147,148]$. LGR5 has been demonstrated as a marker for CSCs in colorectal cancer (CRC) and upregulated in oesophageal adenocarcinoma (EAC), basal cell carcinomas (BCCa) of the face, and cancers of the ovary and liver [143-146, 148150]. Increased expression of LRG5 is correlated to poor survival rates in $\mathrm{CRC}$ and $\mathrm{EAC}$ and linked to increased proliferation and tumour formations in BCC $[143,146,149]$. A study by Morita et al. (2004) found LGR5 expression in the epithelium of the tongue and tissues of the mandible in wild-type mice and reported that knock down of these genes led to ankyloglossia, suggesting the importance of LGR5 in embryonic craniofacial development [151]. Interestingly, LGR5 has also been demonstrated as a marker for incisor stem cells in mice being found in the stellate reticulum compartment in the labial cervical loop [152]. Given that the Wnt/ $\beta$-catenin-signalling pathway has been suggested to be abnormal in a side population of HNSCC cell lines and that LGR5 has been detected in the oral tissues of mice, further investigation into the effect of abnormal Wnt signalling in HNSCC on the expression of LGR5 and its candidature as a CSC marker in HNSCC may yield important insights into the behaviour of CSCs in HNSCC leading to superior prognostic and therapeutic strategies $[129,130]$.

4.3. Other Markers. Musashi-1 (Msi-1) is a translational regulator associated with both stem cell and tumour biology that has been recently correlated with OSCC and stage of carcinogenesis [153-155]. Cripto-1 is an extracellular, GPIanchored signalling protein with important roles during embryonic development, stem cell function, and cancer progression [156-158]. Bone morphogenetic proteins (BMPs) play a diverse role in numerous biological processes [159, 160]. BMPs regulate proliferation, differentiation, and apoptosis during development and play roles in adult tissue maintenance, remodeling, and repair [161-164]. BMP-4 is thought to play roles in both cancer progression and inhibition in numerous human tumours [119, 165-182]. Chondroitin sulfate proteoglycan 4 (CSPG4) is a unique glycoproteinproteoglycan complex that has been implicated in numerous aspects of melanoma cell biology and carcinoma (including HNSCC) with usefulness as a CSC in glioblastoma [183-189]. CXCR4 is a chemokine receptor that has been suggested to contribute to the metastasis of several cancers and has been found to be overexpressed in metastatic HNSCC [190-197]. CD166, present in all three embryological layers, is usually found in cells involved in growth and migration and has been implicated in cancers throughout the body indicating that research into its ability to identify CSCs at different stages of HNSCC may prove very useful [198]. SLC2A13 has been proposed as a putative marker for CSCs in OSCC after it was observed to be overexpressed in sphere formation derived from primary OSCC samples [199]. It has been suggested that podoplanin may be useful as a prognostic marker in the development and progression of head and neck cancer and as a biomarker for oral cancer risk in patients [165-176, 200205]. A recent study of oral erythroplakia has suggested that podoplanin and ABCG2 expression may be beneficial for predicting progression to cancer as $90.9 \%$ of erythroplakic lesions expressing both markers became cancerous, 
while only $30 \%$ which expressed neither marker progressed [177].

\section{Limitations and Implications}

The limitations of current studies in this field are vast and for the most part generalised. This is due to the inherent nature of the research rather than research techniques. The main pitfall of the studies is their small sample size. This is due initially to the difficulty in obtaining primary tissue and further amplified by the even smaller population of CSCs that can be derived from these tissues. In addition to small sample size, most samples are drawn from varying sites of the head and neck region, TNM stage, gender, smoking status, alcohol use, age, and aetiology. Not only does the small sample size amplify these problems, but also it does not allow analysis of results to control for these variables. Although several researchers have attempted to use cell lines in order to bypass the problem of obtaining primary tumours, this does not solve the limitations mentioned and also introduces others. Studies using cell lines have only used a small number of different cell lines, which may not be representative of the total HNSCC population. Taking into account the heterogeneous nature of HNSCC and the potential evolution of the cells contained within these tumours, it seems that such samples are likely to be far from representative $[69,178]$. It has been suggested that a tumour microenvironment or niche plays a large role in its behaviour including effects on growth stimulation, angiogenesis, and immunocompetence $[14,15,179]$. Cell lines effectively remove the tumour from this environment and establish an artificial one which has been constructed entirely to maintain the cell line, rather than to mimic the cell's original environment. The consequence of this confounder may be partially reduced by employing a human dermis-based organotypic culture model, such as the human oral mucosal equivalent (HOME) utilised by Dalley et al. $[119,180]$. The problem with differing microenvironments also brings into question the current gold standard of CSC identification, mouse xenograft models [19]. Once again, the tumorigenic potential of a subset of HNSCC cells in a mouse microenvironment may not be representative of the natural niche of these cells. Currently, there is no single biomarker to define the CSC population accurately for HNSCC. Indeed, it seems a set of markers will be required to more narrowly define this population to achieve the best chance of developing targeted identification and treatment. The expression of the purported markers also needs further investigation over a longitudinal basis as expression of markers may evolve through interaction with the environment as the tumour progresses [181, 182]. Based on research to date, the number of cells needed to initiate tumours after sorting by CSC markers is much higher than in other solid tumours. Additionally, there are many markers that have been identified in other malignancies that have yet to be studied in HNSCC.

The CSC hypothesis represents a fundamental shift in our understanding of the nature and pathogenesis of cancer. This insight requires reevaluation of how we diagnose develop prognoses and effective therapies and how the effectiveness of those therapies are assessed. According to the now widely supported CSC theory, just one CSC may be capable of initiating and progressing the full heterogeneity of a tumour, whereas many non-CSCs cannot. The need for more specific therapeutic targets has emerged, redirecting efforts from eliminating the bulk of differentiated cells from a tumour to the smaller minority of CSCs. Therapies targeting CSCs must overcome the chemoresistance, radioresistance, and immune evasion mechanisms of CSCs [33]. Biomarkers for HNSCC CSCs can hopefully play an integral role in not only understanding their role in the "stemness" of CSCs, but also as possible targets for therapy themselves. Targeted therapy is likely to have a higher therapeutic index and therefore less toxicity than current, less specific treatments [43]. As well as the biomarkers themselves, their signalling pathways and products may serve as targets for their elimination [17]. Another possibility is using nanotechnologies that are able to bypass the efflux mechanisms of these proteins $[17,206]$. The Bmi-1 gene has shown to play an important role in chemoand radioresistance in HNSCC CSCs, with knock down of the gene in $\mathrm{HNSCC} \mathrm{ALDH1}^{+}$cells inhibiting tumourigenicity and enhancing chemo- and radiosensitivity $[42,85]$. The inhibition of binding of CD44 with HA interferes with important steps in tumour development such as inhibition of apoptosis, invasion, and angiogenesis; however the similar prevalence of CD44 in normal and malignant tissues alike highlights the need for ideal therapies to target CSCs while sparing normal stem cells [52]. As with normal stem cells, CSCs may be quiescent until stimulated by the microenvironment; elucidation of this interaction may also provide more specific targets for therapy. HNSCC therapy may also be complicated by the fact that a subpopulation of cells driving the tumour at one point in time may not be the same group at another point in time, indicating a need for longitudinal characterisation of CSCs to further refine treatments [19]. Further understanding of the similarities and differences in biology and resistance mechanisms of normal stem cells and cancer stem cells is needed to develop efficient and effective novel HNSCC therapies. Indeed survival studies need to take into account defined patient subpopulations when reporting correlation of biomarkers with patient survival. A more defined analysis of CSC markers in HNSCC subpopulations undergoing adjuvant therapy should be undertaken to more clearly outline the clinical relationship and usefulness of CSC markers and response to HNSCC therapy.

\section{Summary}

The discovery of CSCs has heralded an exciting era in our understanding of HNSCC with significant implications for diagnosis, prognosis, treatment, and ultimately patient outcomes. Currently, there is no single biomarker to define the CSC population accurately for HNSCC. Indeed, it seems a set of markers will be required to more narrowly define this population to achieve the best chance of developing targeted identification and treatment. The expression of purported markers needs further investigation over a longitudinal basis as expression of markers may evolve through interaction with 
the environment as the tumour progresses. Based on research to date, the number of cells needed to initiate tumours after sorting by CSC markers is much higher than in other solid tumours. Additionally, there are many markers that have been identified in other malignancies that have yet to be studied in HNSCC. Identification of biomarkers for HNSCC CSCs is only the first step in uncovering the nature of the disease as further investigation into the roles and mechanisms of these markers is ultimately needed to provide understanding of the pathogenesis and direction for future treatment. It is clear that further research to define the set of biomarkers for this population of cells is required to ultimately achieve superior detection, diagnosis, prognosis, and treatment outcomes in HNSCC patients.

\section{Conflict of Interests}

The authors do not have any conflict of interests that may bias this work.

\section{Acknowledgment}

The authors acknowledge funding from the Cancer Council of Queensland in support of their work on oral cancer stem cells granted to C. S. F.

\section{References}

[1] S. Warnakulasuriya, "Global epidemiology of oral and oropharyngeal cancer," Oral Oncology, vol. 45, no. 4-5, pp. 309-316, 2009.

[2] C. Scully and J. Bagan, "Oral squamous cell carcinoma overview," Oral Oncology, vol. 45, no. 4-5, pp. 301-308, 2009.

[3] P. Zhang, Y. Zhang, L. Mao, Z. Zhang, and W. Chen, "Side population in oral squamous cell carcinoma possesses tumor stem cell phenotypes," Cancer Letters, vol. 277, no. 2, pp. 227234, 2009.

[4] D. J. Liebertz, M. G. Lechner, R. Masood et al., "Establishment and characterization of a novel head and neck squamous cell carcinoma cell line USC-HN1," Head and Neck Oncology, vol. 2, no. 1, article 5, 2010.

[5] C. M. Sterz, C. Kulle, B. Dakic et al., "A basal-cell-like compartment in head and neck squamous cell carcinomas represents the invasive front of the tumor and is expressing MMP-9," Oral Oncology, vol. 46, no. 2, pp. 116-122, 2010.

[6] M. J. McCullough, G. Prasad, and C. S. Farah, "Oral mucosal malignancy and potentially malignant lesions: an update on the epidemiology, risk factors, diagnosis and management," Australian Dental Journal, vol. 55, pp. 61-65, 2010.

[7] M. E. P. Prince and L. E. Ailles, "Cancer stem cells in head and neck squamous cell cancer," Journal of Clinical Oncology, vol. 26, no. 17, pp. 2871-2875, 2008.

[8] S. H. Chiou, C. C. Yu, C. Y. Huang et al., "Positive correlations of Oct-4 and Nanog in oral cancer stem-like cells and high-grade oral squamous cell carcinoma," Clinical Cancer Research, vol. 14, no. 13, pp. 4085-4095, 2008.

[9] C. Kelly, V. Paleri, C. Downs, and R. Shah, "Deterioration in quality of life and depressive symptoms during radiation therapy for head and neck cancer," Otolaryngology, vol. 136, no. 1, pp. 108-111, 2007.
[10] S. N. Rogers, S. A. Ahad, and A. P. Murphy, "A structured review and theme analysis of papers published on 'quality of life' in head and neck cancer: 2000-2005," Oral Oncology, vol. 43, no. 9, pp. 843-868, 2007.

[11] A. F. Oton-Leite, A. C. Corrêa de Castro, M. O. Morais, J. C. D. Pinezi, C. R. Leles, and E. F. Mendonça, "Effect of intraoral lowlevel laser therapy on quality of life of patients with head and neck cancer undergoing radiotherapy," Head and Neck, vol. 34, no. 3, pp. 398-404, 2012.

[12] L. J. Harper, D. E. Costea, L. Gammon, B. Fazil, A. Biddle, and I. C. Mackenzie, "Normal and malignant epithelial cells with stem-like properties have an extended G2 cell cycle phase that is associated with apoptotic resistance," BMC Cancer, vol. 10, article 166, 2010.

[13] M. H. Wong, M. M. Monroe, E. C. Anderson, and D. R. Clayburgh, "Cancer stem cells in head and neck squamous cell carcinoma," Journal of Oncology, vol. 2011, Article ID 762780, 8 pages, 2011.

[14] A. Umezawa and J. D. Gorham, "Dueling models in head and neck tumor formation," Laboratory Investigation, vol. 90, no. 11, pp. 1546-1548, 2010.

[15] R. J. Ward and P. B. Dirks, "Cancer stem cells: at the headwaters of tumor development," Annual Review of Pathology, vol. 2, pp. 175-189, 2007.

[16] M. E. Prince, R. Sivanandan, A. Kaczorowski et al., "Identification of a subpopulation of cells with cancer stem cell properties in head and neck squamous cell carcinoma," Proceedings of the National Academy of Sciences of the United States of America, vol. 104, no. 3, pp. 973-978, 2007.

[17] Z. Chen, "The cancer stem cell concept in progression of head and neck cancer," Journal of Oncology, vol. 2009, Article ID 894064, 8 pages, 2009.

[18] C. T. Jordan, M. L. Guzman, and M. Noble, "Cancer stem cells," New England Journal of Medicine, vol. 355, no. 12, pp. 1253-1261, 2006.

[19] M. F. Clarke, J. E. Dick, P. B. Dirks et al., "Cancer stem cellsperspectives on current status and future directions: AACR workshop on cancer stem cells," Cancer Research, vol. 66, no. 19, pp. 9339-9344, 2006.

[20] C. T. Jordan, "Cancer stem cells: controversial or just misunderstood?" Cell Stem Cell, vol. 4, no. 3, pp. 203-205, 2009.

[21] S. I. Sayed, R. C. Dwivedi, R. Katna et al., "Implications of understanding cancer stem cell (CSC) biology in head and neck squamous cell cancer," Oral Oncology, vol. 47, no. 4, pp. 237-243, 2011.

[22] D. Bonnet and J. E. Dick, "Human acute myeloid leukemia is organized as a hierarchy that originates from a primitive hematopoietic cell," Nature Medicine, vol. 3, no. 7, pp. 730-737, 1997.

[23] M. Al-Hajj, M. S. Wicha, A. Benito-Hernandez, S. J. Morrison, and M. F. Clarke, "Prospective identification of tumorigenic breast cancer cells," Proceedings of the National Academy of Sciences of the United States of America, vol. 100, no. 7, pp. 39833988, 2003.

[24] E. Charafe-Jauffret, F. Monville, C. Ginestier, G. Dontu, D. Birnbaum, and M. S. Wicha, "Cancer stem cells in breast: current opinion and future challenges," Pathobiology, vol. 75, no. 2, pp. 75-84, 2008.

[25] S. K. Singh, C. Hawkins, I. D. Clarke et al., "Identification of human brain tumour initiating cells," Nature, vol. 432, no. 7015, pp. 396-401, 2004. 
[26] A. T. Collins, P. A. Berry, C. Hyde, M. J. Stower, and N. J. Maitland, "Prospective identification of tumorigenic prostate cancer stem cells," Cancer Research, vol. 65, no. 23, pp. 1094610951, 2005.

[27] L. Xin, D. A. Lawson, and O. N. Witte, “The Sca-1 cell surface marker enriches for a prostate-regenerating cell subpopulation that can initiate prostate tumorigenesis," Proceedings of the National Academy of Sciences of the United States of America, vol. 102, no. 19, pp. 6942-6947, 2005.

[28] A. Eramo, F. Lotti, G. Sette et al., "Identification and expansion of the tumorigenic lung cancer stem cell population," Cell Death and Differentiation, vol. 15, no. 3, pp. 504-514, 2008.

[29] L. Ricci-Vitiani, A. Pagliuca, E. Palio, A. Zeuner, and R. De Maria, "Colon cancer stem cells," Gut, vol. 57, no. 4, pp. 538548, 2008.

[30] C. J. Lee, C. Li, and D. M. Simeone, "Human pancreatic cancer stem cells: implications for how we treat pancreatic cancer," Translational Oncology, vol. 1, pp. 14-18, 2008.

[31] Z. F. Yang, D. W. Ho, M. N. Ng et al., "Significance of CD $90^{+}$ cancer stem cells in human liver cancer," Cancer Cell, vol. 13, no. 2, pp. 153-166, 2008.

[32] D. Fang, T. K. Nguyen, K. Leishear et al., "A tumorigenic subpopulation with stem cell properties in melanomas," Cancer Research, vol. 65, no. 20, pp. 9328-9337, 2005.

[33] A. E. Albers, C. Chen, B. Köberle et al., "Stem cells in squamous head and neck cancer," Critical Reviews in Oncology/Hematology, vol. 81, no. 3, pp. 224-240, 2012.

[34] J. E. Visvader and G. J. Lindeman, "Cancer stem cells in solid tumours: accumulating evidence and unresolved questions," Nature Reviews Cancer, vol. 8, no. 10, pp. 755-768, 2008.

[35] O. Al-Assar, R. J. Muschel, T. S. Mantoni, W. G. McKenna, and T. B. Brunner, "Radiation response of cancer stem-like cells from established human cell lines after sorting for surface markers," International Journal of Radiation Oncology Biology Physics, vol. 75, no. 4, pp. 1216-1225, 2009.

[36] S. Bao, Q. Wu, R. E. McLendon et al., "Glioma stem cells promote radioresistance by preferential activation of the DNA damage response," Nature, vol. 444, no. 7120, pp. 756-760, 2006.

[37] G. Bertolini, L. Roz, P. Perego et al., "Highly tumorigenic lung cancer $\mathrm{CD}_{133^{+}}$cells display stem-like features and are spared by cisplatin treatment," Proceedings of the National Academy of Sciences of the United States of America, vol. 106, no. 38, pp. 16281-16286, 2009.

[38] C. J. Chang, C. C. Hsu, M. C. Yung et al., "Enhanced radiosensitivity and radiation-induced apoptosis in glioma CD133positive cells by knockdown of SirT1 expression," Biochemical and Biophysical Research Communications, vol. 380, no. 2, pp. 236-242, 2009.

[39] M. Diehn and M. F. Clarke, "Cancer stem cells and radiotherapy: new insights into tumor radioresistance," Journal of the National Cancer Institute, vol. 98, no. 24, pp. 1755-1757, 2006.

[40] S. P. Hong, J. Wen, S. Bang, S. Park, and Y. S. Si, “CD44-positive cells are responsible for gemcitabine resistance in pancreatic cancer cells," International Journal of Cancer, vol. 125, no. 10, pp. 2323-2331, 2009.

[41] A. M. McCord, M. Jamal, E. S. Williams, K. Camphausen, and P. J. Tofilon, "CD133 ${ }^{+}$glioblastoma stem-like cells are radiosensitive with a defective DNA damage response compared with established cell lines," Clinical Cancer Research, vol. 15, no. 16, pp. 5145-5153, 2009.
[42] S. H. Chiou, C. C. Yu, W. L. Lo et al., "Bmi-1 regulates snail expression and promotes metastasis ability in head and neck squamous cancer-derived ALDH1 positive cells," Journal of Oncology, vol. 2011, Article ID 609259, 16 pages, 2011.

[43] M. Damek-Poprawa, A. Volgina, J. Korostoff et al., "Targeted inhibition of $\mathrm{CD} 133^{+}$cells in oral cancer cell lines," Journal of Dental Research, vol. 90, no. 5, pp. 638-645, 2011.

[44] M. Baumann, M. Krause, and R. Hill, "Exploring the role of cancer stem cells in radioresistance," Nature Reviews Cancer, vol. 8, no. 7, pp. 545-554, 2008.

[45] N. Y. Frank, T. Schatton, and M. H. Frank, "The therapeutic promise of the cancer stem cell concept," Journal of Clinical Investigation, vol. 120, no. 1, pp. 41-50, 2010.

[46] P. Dalerba, R. W. Cho, and M. F. Clarke, "Cancer stem cells: models and concepts," Annual Review of Medicine, vol. 58, pp. 267-284, 2007.

[47] Z. A. Rasheed, J. Kowalski, B. D. Smith, and W. Matsui, "Concise review: emerging concepts in clinical targeting of cancer stem cells," Stem Cells, vol. 29, no. 6, pp. 883-887, 2011.

[48] B. Baum, J. Settleman, and M. P. Quinlan, "Transitions between epithelial and mesenchymal states in development and disease," Seminars in Cell and Developmental Biology, vol. 19, no. 3, pp. 294-308, 2008.

[49] T. Brabletz, A. Jung, S. Spaderna, F. Hlubek, and T. Kirchner, "Migrating cancer stem cells-an integrated concept of malignant tumour progression," Nature Reviews Cancer, vol. 5, no. 9, pp. 744-749, 2005.

[50] C. Chen, Y. Wei, M. Hummel et al., "Evidence for epithelialmesenchymal transition in cancer stem cells of head and neck squamous cell carcinoma," PLoS ONE, vol. 6, no. 1, Article ID e16466, 2011.

[51] S. J. Davis, V. Divi, J. H. Owen et al., "Metastatic potential of cancer stem cells in head and neck squamous cell carcinoma," Archives of Otolaryngology, vol. 136, no. 12, pp. 1260-1266, 2010.

[52] V. Orian-Rousseau, "CD44, a therapeutic target for metastasising tumours," European Journal of Cancer, vol. 46, no. 7, pp. 1271-1277, 2010.

[53] R. Pang, W. L. Law, A. C. Y. Chu et al., "A subpopulation of CD $26^{+}$cancer stem cells with metastatic capacity in human colorectal cancer," Cell Stem Cell, vol. 6, no. 6, pp. 603-615, 2010.

[54] S. Sun and Z. Wang, "Head neck squamous cell carcinoma c$\mathrm{Met}^{+}$cells display cancer stem cell properties and are responsible for cisplatin-resistance and metastasis," International Journal of Cancer, vol. 129, no. 10, pp. 2337-2348, 2011.

[55] D. C. Radisky and M. A. LaBarge, "Epithelial-mesenchymal transition and the stem cell phenotype," Cell Stem Cell, vol. 2, no. 6, pp. 511-512, 2008.

[56] A. Mishra and M. Verma, "Cancer biomarkers: are we ready for the prime time?” Cancers, vol. 2, no. 1, pp. 190-208, 2010.

[57] K. Chikamatsu, G. Takahashi, K. Sakakura, S. Ferrone, and K. Masuyama, "Immunoregulatory properties of $\mathrm{CD} 44^{+}$cancer stem-like cells in squamous cell carcinoma of the head and neck," Head and Neck, vol. 33, no. 2, pp. 208-215, 2011.

[58] Q. Yu, B. P. Toole, and I. Stamenkovic, "Induction of apoptosis of metastatic mammary carcinoma cells invivo by disruption of tumor cell surface CD44 function," Journal of Experimental Medicine, vol. 186, no. 12, pp. 1985-1996, 1997.

[59] Q. Yu and I. Stamenkovic, "Localization of matrix metalloproteinase 9 to the cell surface provides a mechanism for CD44mediated tumor invasion," Genes and Development, vol. 13, no. 1, pp. 35-48, 1999. 
[60] H. R. Kim, M. A. Wheeler, C. M. Wilson et al., "Hyaluronan facilitates invasion of colon carcinoma cells in vitro via interaction with CD44," Cancer Research, vol. 64, no. 13, pp. 4569-4576, 2004.

[61] R. Golshani, L. Lopez, V. Estrella, M. Kramer, N. Iida, and V. B. Lokeshwar, "Hyaluronic acid synthase-1 expression regulates bladder cancer growth, invasion, and angiogenesis through CD44," Cancer Research, vol. 68, no. 2, pp. 483-491, 2008.

[62] M. Kajita, Y. Itoh, T. Chiba et al., "Membrane-type 1 matrix metalloproteinase cleaves CD44 and promotes cell migration," Journal of Cell Biology, vol. 153, no. 5, pp. 893-904, 2001.

[63] C. M. Isacke and H. Yarwood, "The hyaluronan receptor, CD44," International Journal of Biochemistry and Cell Biology, vol. 34, no. 7, pp. 718-721, 2002.

[64] P. Dalerba, S. J. Dylla, I. K. Park et al., "Phenotypic characterization of human colorectal cancer stem cells," Proceedings of the National Academy of Sciences of the United States of America, vol. 104, no. 24, pp. 10158-10163, 2007.

[65] C. Li, D. G. Heidt, P. Dalerba et al., "Identification of pancreatic cancer stem cells," Cancer Research, vol. 67, no. 3, pp. 1030-1037, 2007.

[66] C. A. O’Brien, A. Pollett, S. Gallinger, and J. E. Dick, "A human colon cancer cell capable of initiating tumour growth in immunodeficient mice," Nature, vol. 445, no. 7123, pp. 106-110, 2007.

[67] S. K. Singh, I. D. Clarke, M. Terasaki et al., "Identification of a cancer stem cell in human brain tumors," Cancer Research, vol. 63, no. 18 , pp. 5821-5828, 2003.

[68] A. Okamoto, K. Chikamatsu, K. Sakakura, K. Hatsushika, G. Takahashi, and K. Masuyama, "Expansion and characterization of cancer stem-like cells in squamous cell carcinoma of the head and neck," Oral Oncology, vol. 45, no. 7, pp. 633-639, 2009.

[69] L. J. Harper, K. Piper, J. Common, F. Fortune, and I. C. Mackenzie, "Stem cell patterns in cell lines derived from head and neck squamous cell carcinoma," Journal of Oral Pathology and Medicine, vol. 36, no. 10, pp. 594-603, 2007.

[70] L. Gammon, A. Biddle, B. Fazil, L. Harper, and I. C. Mackenzie, "Stem cell characteristics of cell sub-populations in cell lines derived from head and neck cancers of Fanconi anemia patients," Journal of Oral Pathology and Medicine, vol. 40, no. 2, pp. 143-152, 2011.

[71] Y. C. Chen, Y. W. Chen, H. S. Hsu et al., "Aldehyde dehydrogenase 1 is a putative marker for cancer stem cells in head and neck squamous cancer," Biochemical and Biophysical Research Communications, vol. 385, no. 3, pp. 307-313, 2009.

[72] B. Joshua, M. J. Kaplan, I. Doweck, R. Pai, I. L. Weissman, and L. E. Ailles, "Frequency of cells expressing CD44, a Head and Neck cancer stem cell marker: correlation with tumor aggressiveness," Head and Neck, vol. 34, no. 1, pp. 42-49, 2012.

[73] L. R. Oliveira, J. P. Oliveira-Costa, I. M. Araujo et al., "Cancer stem cell immunophenotypes in oral squamous cell carcinoma," Journal of Oral Pathology and Medicine, vol. 40, no. 2, pp. 135142, 2011.

[74] J. Su, X. H. Xu, Q. Huang et al., "Identification of cancer stemlike $\mathrm{CD} 44^{+}$cells in human nasopharyngeal carcinoma cell line," Archives of Medical Research, vol. 42, no. 1, pp. 15-21, 2011.

[75] S. J. Wang, G. Wong, A. M. De Heer, W. Xia, and L. Y. W. Bourguignon, "CD44 Variant isoforms in head and neck squamous cell carcinoma progression," Laryngoscope, vol. 119, no. 8, pp. 1518-1530, 2009.
[76] L. L. Kokko, S. Hurme, S. M. Maula et al., "Significance of sitespecific prognosis of cancer stem cell marker CD44 in head and neck squamous-cell carcinoma," Oral Oncology, vol. 47, no. 6, pp. 510-516, 2011.

[77] J. T. Lin, T. H. Chang, C. S. Chang et al., "Prognostic value of pretreatment CD44 mRNA in peripheral blood of patients with locally advanced head and neck cancer," Oral Oncology, vol. 46, no. 5, pp. e29-e33, 2010.

[78] B. Mack and O. Gires, "CD44s and CD44v6 expression in head and neck epithelia," PLoS ONE, vol. 3, no. 10, Article ID e3360, 2008.

[79] Y. C. Lim, S. Y. Oh, Y. Y. Cha, S. H. Kim, X. Jin, and H. Kim, "Cancer stem cell traits in squamospheres derived from primary head and neck squamous cell carcinomas," Oral Oncology, vol. 47, no. 2, pp. 83-91, 2011.

[80] M. R. Clay, M. Tabor, J. H. Owen et al., "Single-marker identification of head and neck squamous cell carcinoma cancer stem cells with aldehyde dehydrogenase," Head and Neck, vol. 32, no. 9, pp. 1195-1201, 2010.

[81] C. Ginestier, M. H. Hur, E. Charafe-Jauffret et al., "ALDH1 is a marker of normal and malignant human mammary stem cells and a predictor of poor clinical outcome," Cell Stem Cell, vol. 1, no. 5, pp. 555-567, 2007.

[82] E. H. Huang, M. J. Hynes, T. Zhang et al., "Aldehyde dehydrogenase 1 is a marker for normal and malignant human colonic stem cells (SC) and tracks SC overpopulation during colon tumorigenesis," Cancer Research, vol. 69, no. 8, pp. 3382-3389, 2009.

[83] F. Jiang, Q. Qiu, A. Khanna et al., "Aldehyde dehydrogenase 1 is a tumor stem cell-Associated marker in lung cancer," Molecular Cancer Research, vol. 7, no. 3, pp. 330-338, 2009.

[84] S. Ma, W. C. Kwok, T. K. W. Lee et al., "Aldehyde dehydrogenase discriminates the CD133 liver cancer stem cell populations," Molecular Cancer Research, vol. 6, no. 7, pp. 1146-1153, 2008.

[85] Y. C. Chen, C. J. Chang, H. S. Hsu et al., "Inhibition of tumorigenicity and enhancement of radiochemosensitivity in head and neck squamous cell cancer-derived ALDH1-positive cells by knockdown of Bmi-1," Oral Oncology, vol. 46, no. 3, pp. 158-165, 2010.

[86] M. I. Koukourakis, A. Giatromanolaki, V. Tsakmaki, and E. Sivridis, "Cancer stem cell phenotype relates to radiochemotherapy outcome in locally advanced squamous cell head-neck cancer," British Journal of Cancer, vol. 106, no. 5, pp. 846-853, 2012.

[87] Y. Wu and P. Y. Wu, "CD133 as a marker for cancer stem cells: progresses and concerns," Stem Cells and Development, vol. 18, no. 8, pp. 1127-1134, 2009.

[88] Q. Zhang, S. Shi, Y. Yen, J. Brown, J. Q. Ta, and A. D. Le, “A subpopulation of $\mathrm{CD}_{133^{+}}$cancer stem-like cells characterized in human oral squamous cell carcinoma confer resistance to chemotherapy," Cancer Letters, vol. 289, no. 2, pp. 151-160, 2010.

[89] X. D. Wei, L. Zhou, L. Cheng, J. Tian, J. J. Jiang, and J. MacCallum, "In vivo investigation of CD133 as a putative marker of cancer stem cells in hep-2 cell line," Head and Neck, vol. 31, no. 1, pp. 94-101, 2009.

[90] Y. Sun, J. Han, Y. Lu, X. Yang, and M. Fan, "Biological characteristics of a cell subpopulation in tongue squamous cell carcinoma," Oral Diseases, vol. 18, no. 2, pp. 169-177, 2012.

[91] S. V. Shmelkov, J. M. Butler, A. T. Hooper et al., "CD133 expression is not restricted to stem cells, and both $\mathrm{CD}_{133^{+}}$and CD133- metastatic colon cancer cells initiate tumors," Journal of Clinical Investigation, vol. 118, no. 6, pp. 2111-2120, 2008. 
[92] J. Wang, P. Ø. Sakariassen, O. Tsinkalovsky et al., “CD133 negative glioma cells form tumors in nude rats and give rise to CD133 positive cells," International Journal of Cancer, vol. 122, no. 4, pp. 761-768, 2008.

[93] A. T. Ogden, A. E. Waziri, R. A. Lochhead et al., "Identification of A2B5+CD133-tumor-initiating cells in adult human gliomas," Neurosurgery, vol. 62, no. 2, pp. 505-514, 2008.

[94] M. A. LaBarge and M. J. Bissell, "Is CD133 a marker of metastatic colon cancer stem cells?" Journal of Clinical Investigation, vol. 118, no. 6, pp. 2021-2024, 2008.

[95] Y. C. Lim, J. H. Han, H. J. Kang, E. C. Choi, and C.-H. Kim, "Overexpression of c-Met promotes invasion and metastasis of small oral tongue carcinoma," Oral Oncology, vol. 48, no. 11, pp. 1114-1119, 2012.

[96] D. Zhao, S.-H. Wang, Y. Feng, C.-G. Hua, J. Zhao, and X.-F. Tang, "Intratumoral c-Met expression is associated with vascular endothelial growth factor $\mathrm{C}$ expression, lymphangiogenesis, and lymph node metastasis in oral squamous cell carcinoma: implications for use as a prognostic marker," Human Pathology, vol. 42, no. 10, pp. 1514-1523, 2011.

[97] J. Dou and N. Gu, "Emerging strategies for the identification and targeting of cancer stem cells," Tumor Biology, vol. 31, no. 4, pp. 243-253, 2010.

[98] W. Liu, J.-Q. Feng, X.-M. Shen, H.-Y. Wang, Y. Liu, and Z.T. Zhou, "Two stem cell markers, ATP-binding cassette, G2 subfamily (ABCG2) and BMI-1, predict the transformation of oral leukoplakia to cancer: a long-term follow-up study," Cancer, vol. 118, no. 6, pp. 1693-1700, 2012.

[99] M. Grimm, M. Krimmel, J. Polligkeit et al., “ABCB5 expression and cancer stem cell hypothesis in oral squamous cell carcinoma," European Journal of Cancer, vol. 48, no. 17, pp. 3186-3197, 2012.

[100] Y. S. Chan, L. Yang, and H. H. Ng, "Transcriptional regulatory networks in embryonic stem cells," Progress in Drug Research, vol. 67, pp. 239-252, 2011.

[101] X. Wang, Y. Wang, L. Yu et al., "CSPG4 in cancer: multiple roles," Current Molecular Medicine, vol. 10, no. 4, pp. 419-429, 2010.

[102] S. Ohtsuka and S. Dalton, "Molecular and biological properties of pluripotent embryonic stem cells," Gene Therapy, vol. 15, no. 2, pp. 74-81, 2008.

[103] K. Okamoto, H. Okazawa, A. Okuda, M. Sakai, M. Muramatsu, and H. Hamada, "A novel octamer binding transcription factor is differentially expressed in mouse embryonic cells," Cell, vol. 60, no. 3, pp. 461-472, 1990.

[104] M. H. Rosner, M. A. Vigano, K. Ozato et al., "A POU-domain transcription factor in early stem cells and germ cells of the mammalian embryo," Nature, vol. 345 , no. 6277, pp. 686-692, 1990.

[105] I. Chambers, D. Colby, M. Robertson et al., "Functional expression cloning of Nanog, a pluripotency sustaining factor in embryonic stem cells," Cell, vol. 113, no. 5, pp. 643-655, 2003.

[106] K. Mitsui, Y. Tokuzawa, H. Itoh et al., “The homeoprotein nanog is required for maintenance of pluripotency in mouse epiblast and ES cells," Cell, vol. 113, no. 5, pp. 631-642, 2003.

[107] A. A. Avilion, S. K. Nicolis, L. H. Pevny, L. Perez, N. Vivian, and R. Lovell-Badge, "Multipotent cell lineages in early mouse development depend on SOX2 function," Genes and Development, vol. 17, no. 1, pp. 126-140, 2003.

[108] K. Okita, T. Ichisaka, and S. Yamanaka, "Generation of germline-competent induced pluripotent stem cells," Nature, vol. 448, no. 7151, pp. 313-317, 2007.
[109] I. H. Park, R. Zhao, J. A. West et al., "Reprogramming of human somatic cells to pluripotency with defined factors," Nature, vol. 451, no. 7175, pp. 141-146, 2008.

[110] J. Yu, M. A. Vodyanik, K. Smuga-Otto et al., "Induced pluripotent stem cell lines derived from human somatic cells," Science, vol. 318, no. 5858, pp. 1917-1920, 2007.

[111] J. Nichols, B. Zevnik, K. Anastassiadis et al., "Formation of pluripotent stem cells in the mammalian embryo depends on the POU transcription factor Oct4," Cell, vol. 95, no. 3, pp. 379391, 1998.

[112] S. Gidekel, G. Pizov, Y. Bergman, and E. Pikarsky, "Oct-3/4 is a dose-dependent oncogenic fate determinant," Cancer Cell, vol. 4, no. 5, pp. 361-370, 2003.

[113] M. H. Tai, C. C. Chang, L. K. Olson, and J. E. Trosko, "Oct4 expression in adult human stem cells: evidence in support of the stem cell theory of carcinogenesis," Carcinogenesis, vol. 26, no. 2, pp. 495-502, 2005.

[114] G. I. Abelev and N. L. Lazarevich, "Control of differentiation in progression of epithelial tumors," Advances in Cancer Research, vol. 95, pp. 61-113, 2006.

[115] A. Siu, C. Lee, D. Dang, C. Lee, and D. M. Ramos, "Stem cell markers as predictors of oral cancer invasion," Anticancer Research, vol. 32, no. 4, pp. 1163-1166, 2012.

[116] L.-L. Tsai, C.-C. Yu, and Y.-C. Chang, "Markedly increased Oct4 and Nanog expression correlates with cisplatin resistance in oral squamous cell carcinoma," Journal of Oral Pathology and Medicine, vol. 40, no. 8, pp. 621-628, 2011.

[117] N. Ge, H. X. Lin, X. S. Xiao et al., "Prognostic significance of Oct4 and Sox 2 expression in hypopharyngeal squamous cell carcinoma," Journal of Translational Medicine, vol. 8, article 94, 2010.

[118] A. J. Bass, H. Watanabe, C. H. Mermel et al., "SOX2 is an amplified lineage-survival oncogene in lung and esophageal squamous cell carcinomas," Nature Genetics, vol. 41, no. 11, pp. 1238-1242, 2009.

[119] A. J. Dalley, Z. Upton, and C. S. Farah, "Organotypic culture of normal, dysplastic and squamous cell carcinoma-derived oral cell lines reveals loss of spatial regulation of CD 44 and $p 75^{\text {NTR }}$ in malignancy," Journal of Oral Pathology and Medicine, vol. 42, no. 1, pp. 37-46, 2013.

[120] J. P. Thiery, "Epithelial-mesenchymal transitions in development and pathologies," Current Opinion in Cell Biology, vol. 15, no. 6, pp. 740-746, 2003.

[121] J. P. Thiery and J. P. Sleeman, "Complex networks orchestrate epithelial-mesenchymal transitions," Nature Reviews Molecular Cell Biology, vol. 7, no. 2, pp. 131-142, 2006.

[122] T. Tsuji, S. Ibaragi, K. Shima et al., "Epithelial-mesenchymal transition induced by growth suppressor p12 CDK2-AP1 promotes tumor cell local invasion but suppresses distant colony growth," Cancer Research, vol. 68, no. 24, pp. 10377-10386, 2008.

[123] M. E. Kupferman, T. Jiffar, A. El-Naggar et al., “TrkB induces EMT and has a key role in invasion of head and neck squamous cell carcinoma," Oncogene, vol. 29, no. 14, pp. 2047-2059, 2010.

[124] M. J. Blanco, G. Moreno-Bueno, D. Sarrio et al., "Correlation of Snail expression with histological grade and lymph node status in breast carcinomas," Oncogene, vol. 21, no. 20, pp. 3241-3246, 2002.

[125] M. A. Ginos, G. P. Page, B. S. Michalowicz et al., "Identification of a gene expression signature associated with recurrent disease in squamous cell carcinoma of the head and neck," Cancer Research, vol. 64, no. 1, pp. 55-63, 2004. 
[126] J. Yang, S. A. Mani, and R. A. Weinberg, "Exploring a new twist on tumor metastasis," Cancer Research, vol. 66, no. 9, pp. 4549$4552,2006$.

[127] M. H. Yang, M. Z. Wu, S. H. Chiou et al., "Direct regulation of TWIST by HIF-1 $\alpha$ promotes metastasis," Nature Cell Biology, vol. 10, no. 3, pp. 295-305, 2008.

[128] D. Meulemans and M. Bronner-Fraser, "Gene-regulatory interactions in neural crest evolution and development," Developmental Cell, vol. 7, no. 3, pp. 291-299, 2004.

[129] T. Reya and H. Clevers, "Wnt signalling in stem cells and cancer," Nature, vol. 434, no. 7035, pp. 843-850, 2005.

[130] J. Song, I. Chang, Z. Chen, M. Kang, and C. Y. Wang, "Characterization of side populations in HNSCC: highly invasive, chemoresistant and abnormal Wnt signaling," PLoS ONE, vol. 5, no. 7, Article ID el1456, 2010.

[131] P.-Y. Chu, F.-W. Hu, C. C. Yu et al., "Epithelial-mesenchymal transition transcription factor ZEB1/ZEB2 co-expression predicts poor prognosis and maintains tumor-initiating properties in head and neck cancer," Oral Oncology, vol. 49, no. 1, pp. 34-41, 2013.

[132] V. Häyry, L. K. Mäkinen, T. Atula et al., "Bmi-1 expression predicts prognosis in squamous cell carcinoma of the tongue," British Journal of Cancer, vol. 102, no. 5, pp. 892-897, 2010.

[133] M. K. Kang, R. H. Kim, S. J. Kim et al., "Elevated Bmi1 expression is associated with dysplastic cell transformation during oral carcinogenesis and is required for cancer cell replication and survival," British Journal of Cancer, vol. 96, no. 1, pp. 126-133, 2007.

[134] C. Y. Chen, S. H. Chiou, C. Y. Huang et al., "Distinct population of highly malignant cells in a head and neck squamous cell carcinoma cell line established by xenograft model," Journal of Biomedical Science, vol. 16, no. 1, article 100, 2009.

[135] K. Chikamatsu, H. Ishii, G. Takahashi et al., "Resistance to apoptosis-inducing stimuli in $\mathrm{CD} 44^{+}$head and neck squamous cell carcinoma cells," Head and Neck, vol. 34, no. 3, pp. 336-343, 2011.

[136] G. Ganguli-Indra, C. Wasylyk, X. Liang et al., "CTIP2 expression in human head and neck squamous cell carcinoma is linked to poorly differentiated tumor status," PLoS ONE, vol. 4, no. 4, Article ID e5367, 2009.

[137] W. L. Lo, C. C. Yu, G. Y. Chiou et al., "MicroRNA-200c attenuates tumour growth and metastasis of presumptive head and neck squamous cell carcinoma stem cells," Journal of Pathology, vol. 223, no. 4, pp. 482-495, 2011.

[138] H. Chen, L. Zhou, G. Wan, T. Dou, and J. Tian, "BMI1 promotes the progression of laryngeal squamous cell carcinoma," Oral Oncology, vol. 47, no. 6, pp. 472-481, 2011.

[139] P. Attner, J. Du, A. Näsman et al., "The role of human papillomavirus in the increased incidence of base of tongue cancer," International Journal of Cancer, vol. 126, no. 12, pp. 2879-2884, 2010.

[140] X. H. Liang, J. Lewis, R. Foote, D. Smith, and D. Kademani, "Prevalence and significance of human papillomavirus in oral tongue cancer: the Mayo Clinic Experience," Journal of Oral and Maxillofacial Surgery, vol. 66, no. 9, pp. 1875-1880, 2008.

[141] S. S. Zeki, T. A. Graham, and N. A. Wright, "Stem cells and their implications for colorectal cancer," Nature Reviews Gastroenterology and Hepatology, vol. 8, no. 2, pp. 90-100, 2011.

[142] N. Barker, J. H. van Es, J. Kuipers et al., "Identification of stem cells in small intestine and colon by marker gene Lgr5," Nature, vol. 449, no. 7165, pp. 1003-1007, 2007.
[143] B. H. A. Von Rahden, S. Kircher, M. Lazariotou et al., "LgR5 expression and cancer stem cell hypothesis: clue to define the true origin of esophageal adenocarcinomas with and without Barrett's Esophagus?" Journal of Experimental and Clinical Cancer Research, vol. 30, no. 1, article 23, 2011.

[144] T. McClanahan, S. Koseoglu, K. Smith et al., "Identification of overexpression of orphan G Protein-Coupled Receptor GPR49 in human colon and ovarian primary tumors," Cancer Biology and Therapy, vol. 5, no. 4, pp. 419-426, 2006.

[145] Y. Yamamoto, M. Sakamoto, G. Fujii et al., "Overexpression of orphan G-protein-coupled receptor, Gpr49, in human hepatocellular carcinomas with $\beta$-catenin mutations," Hepatology, vol. 37, no. 3, pp. 528-533, 2003.

[146] H. Takahashi, H. Ishii, N. Nishida et al., "Significance of Lgr5 ${ }^{+v e}$ cancer stem cells in the colon and rectum," Annals of Surgical Oncology, vol. 18, no. 4, pp. 1166-1174, 2011.

[147] N. Barker and H. Clevers, "Leucine-rich repeat-containing G-protein-coupled receptors as markers of adult stem cells," Gastroenterology, vol. 138, no. 5, pp. 1681-1696, 2010.

[148] A. Haegebarth and H. Clevers, "Wnt signaling, Lgr5, and stem cells in the intestine and skin," American Journal of Pathology, vol. 174, no. 3, pp. 715-721, 2009.

[149] K. Tanese, M. Fukuma, T. Yamada et al., "G-protein-coupled receptor GPR49 is up-regulated in basal cell carcinoma and promotes cell proliferation and tumor formation," American Journal of Pathology, vol. 173, no. 3, pp. 835-843, 2008.

[150] M. van de Wetering, E. Sancho, C. Verweij et al., "The $\beta$ catenin/TCF-4 complex imposes a crypt progenitor phenotype on colorectal cancer cells," Cell, vol. 111, no. 2, pp. 241-250, 2002.

[151] H. Morita, S. Mazerbourg, D. M. Bouley et al., "Neonatal lethality of LGR5 null mice is associated with ankyloglossia and gastrointestinal distension," Molecular and Cellular Biology, vol. 24, no. 22, pp. 9736-9743, 2004.

[152] M. Suomalainen and I. Thesleff, "Patterns of Wnt pathway activity in the mouse incisor indicate absence of Wnt/ $\beta$-catenin signaling in the epithelial stem cells," Developmental Dynamics, vol. 239, no. 1, pp. 364-372, 2010.

[153] H. Kawahara, T. Imai, H. Imataka, M. Tsujimoto, K. Matsumoto, and H. Okano, "Neural RNA-binding protein Musashil inhibits translation initiation by competing with eIF4G for PABP," Journal of Cell Biology, vol. 181, no. 4, pp. 639-653, 2008.

[154] X. Y. Wang, Y. Yin, H. Yuan, T. Sakamaki, H. Okano, and R. I. Glazer, "Musashil modulates mammary progenitor cell expansion through proliferin-mediated activation of the wnt and notch pathways," Molecular and Cellular Biology, vol. 28, no. 11, pp. 3589-3599, 2008.

[155] S. M. Sureban, R. May, R. J. George et al., "Knockdown of RNA binding protein musashi-1 leads to tumor regression in vivo," Gastroenterology, vol. 134, no. 5, pp. 1448-1458, 2008.

[156] C. Bianco, L. Strizzi, N. Normanno, N. Khan, and D. S. Salomon, "Cripto-1: an oncofetal gene with many faces," Current Topics in Developmental Biology, vol. 67, pp. 85-133, 2005.

[157] O. Adewumi, B. Aflatoonian, L. Ahrlund-Richter et al., "Characterization of human embryonic stem cell lines by the International Stem Cell Initiative," Nature Biotechnology, vol. 25, no. 7, pp. 803-816, 2007.

[158] L. Strizzi, C. Bianco, N. Normanno, and D. Salomon, "Cripto1: a multifunctional modulator during embryogenesis and oncogenesis," Oncogene, vol. 24, no. 37, pp. 5731-5741, 2005.

[159] R. Montesano, R. Sarközi, and H. Schramek, "Bone morphogenetic protein- 4 strongly potentiates growth factor-induced 
proliferation of mammary epithelial cells," Biochemical and Biophysical Research Communications, vol. 374, no. 1, pp. 164168, 2008.

[160] D. Su, S. Zhu, X. Han et al., "BMP4-Smad signaling pathway mediates adriamycin-induced premature senescence in lung cancer cells," Journal of Biological Chemistry, vol. 284, no. 18, pp. 12153-12164, 2009.

[161] J. M. Ketolainen, E. L. Alarmo, V. J. Tuominen, and A. Kallioniemi, "Parallel inhibition of cell growth and induction of cell migration and invasion in breast cancer cells by bone morphogenetic protein 4," Breast Cancer Research and Treatment, vol. 124, no. 2, pp. 377-386, 2010.

[162] B. L. M. Hogan, "Bone morphogenetic proteins in development," Current Opinion in Genetics and Development, vol. 6, no. 4, pp. 432-438, 1996.

[163] W. Balemans and W. van Hul, "Extracellular regulation of BMP signaling in vertebrates: a cocktail of modulators," Developmental Biology, vol. 250, no. 2, pp. 231-250, 2002.

[164] D. Chen, M. Zhao, and G. R. Mundy, "Bone morphogenetic proteins," Growth Factors, vol. 22, no. 4, pp. 233-241, 2004.

[165] A. B. Villaret, A. Schreiber, F. Facchetti et al., "Immunostaining patterns of CD31 and podoplanin in previously untreated advanced oral/oropharyngeal cancer: prognostic implications," Head and Neck, vol. 32, no. 6, pp. 786-792, 2010.

[166] L. Vormittag, D. Thurnher, S. Geleff et al., "Co-expression of Bmi-1 and podoplanin predicts overall survival in patients with squamous cell carcinoma of the head and neck treated with radio(chemo)therapy," International Journal of Radiation Oncology Biology Physics, vol. 73, no. 3, pp. 913-918, 2009.

[167] C. Margaritescu, M. Raica, D. Pirici et al., "Podoplanin expression in tumor-free resection margins of oral squamous cell carcinomas: an immunohistochemical and fractal analysis study," Histology and Histopathology, vol. 25, no. 6, pp. 701-711, 2010.

[168] M. Kreppel, U. Drebber, I. Wedemeyer et al., "Podoplanin expression predicts prognosis in patients with oral squamous cell carcinoma treated with neoadjuvant radiochemotherapy," Oral Oncology, vol. 47, no. 9, pp. 873-878, 2011.

[169] H. Kawaguchi, A. K. El-Naggar, V. Papadimitrakopoulou et al., "Podoplanin: a novel marker for oral cancer risk in patients with oral premalignancy," Journal of Clinical Oncology, vol. 26, no. 3, pp. 354-360, 2008.

[170] P. Shi, W. Liu, Z. T. Zhou, Q. B. He, and W. W. Jiang, "Podoplanin and ABCG2: malignant transformation risk markers for oral lichen planus," Cancer Epidemiology Biomarkers and Prevention, vol. 19, no. 3, pp. 844-849, 2010.

[171] L. M. Abbey, G. E. Kaugars, J. C. Gunsolley et al., "Intraexaminer and interexaminer reliability in the diagnosis of oral epithelial dysplasia," Oral Surgery, Oral Medicine, Oral Pathology, Oral Radiology and, vol. 80, no. 2, pp. 188-191, 1995.

[172] S. F. De Sousa, F. O. Gleber-Netto, H. H. De Oliveira-Neto, A. C. Batista, M. H. Nogueira Guimarães Abreu, and M. C. F. De Aguiar, "Lymphangiogenesis and podoplanin expression in oral squamous cell carcinoma and the associated lymph nodes," Applied Immunohistochemistry and Molecular Morphology, vol. 20, no. 6, pp. 588-594, 2012.

[173] R. E. Friedrich, S. Bartel-Friedrich, and C. Hagel, "Expression of podoplanin in primary and metastatic poorly differentiated and undifferentiated carcinomas of the head and neck," Anticancer Research, vol. 32, no. 5, pp. 2019-2022, 2012.

[174] H. Inoue, Y. Miyazaki, K. Kikuchi et al., "Podoplanin expression during dysplasia-carcinoma sequence in the oral cavity," Tumor Biology, vol. 33, no. 1, pp. 183-194, 2012.
[175] M. Kreppel, I. Wedemeyer, C. Mauch, J. E. Zöller, and M. Scheer, "Podoplanin expression in cutaneous head and neck squamous cell carcinoma-prognostic value and clinicopathologic implications," Journal of Surgical Oncology, 2012.

[176] Y. Shimamura, T. Abe, M. Nakahira, T. Yoda, and S.-I. Murata, "Immunohistochemical analysis of oral dysplasia: diagnostic assessment by fascin and podoplanin expression," Acta Histochemica et Cytochemica, vol. 44, no. 6, pp. 239-245, 2011.

[177] J.-Q. Feng, J.-G. Mi, L. Wu et al., "Expression of podoplanin and ABCG2 in oral erythroplakia correlate with oral cancer development," Oral Oncology, vol. 48, no. 9, pp. 848-852, 2012.

[178] A. B. Hjelmeland and J. N. Rich, "The quest for self-identity: not all cancer stem cells are the same," Clinical Cancer Research, vol. 18, no. 13, pp. 3495-3498, 2012.

[179] S. Krishnamurthy, Z. Dong, D. Vodopyanov et al., "Endothelial cell-initiated signaling promotes the survival and self-renewal of cancer stem cells," Cancer Research, vol. 70, no. 23, pp. 99699978, 2010.

[180] K. Moharamzadeh, I. M. Brook, R. van Noort, A. M. Scutt, and M. H. Thornhill, "Tissue-engineered oral mucosa: a review of the scientific literature," Journal of Dental Research, vol. 86, no. 2, pp. 115-124, 2007.

[181] C. Geissler, M. Hambek, M. Leinung et al., "The challenge of tumor heterogeneity-different phenotypes of cancer stem cells in a head and neck squamous cell carcinoma xenograft mouse model," In Vivo, vol. 26, no. 4, pp. 593-598, 2012.

[182] T. Wang, C. W. Ong, J. Shi et al., "Sequential expression of putative stem cell markers in gastric carcinogenesis," British Journal of Cancer, vol. 105, no. 5, pp. 658-665, 2011.

[183] C. Erfurt, E. Müller, S. Emmerling et al., "Melanoma-associated chondroitin sulphate proteoglycan as a new target antigen for $\mathrm{CD}^{+}{ }^{+} \mathrm{T}$ cells in melanoma patients," International Journal of Cancer, vol. 124, no. 10, pp. 2341-2346, 2009.

[184] T. F. Bumol and R. A. Reisfeld, "Unique glycoproteinproteoglycan complex defined by monoclonal antibody on human melanoma cells," Proceedings of the National Academy of Sciences of the United States of America, vol. 79, no. 4 I, pp. 1245-1249, 1982.

[185] W. B. Stallcup, “The NG2 antigen, a putative lineage marker: immunofluorescent localization in primary cultures of rat brain," Developmental Biology, vol. 83, no. 1, pp. 154-165, 1981.

[186] G. Pluschke, M. vanek, A. Evans et al., "Molecular cloning of a human melanoma-associated chondroitin sulfate proteoglycan," Proceedings of the National Academy of Sciences of the United States of America, vol. 93, no. 18, pp. 9710-9715, 1996.

[187] M. A. Burg, K. A. Grako, and W. B. Stallcup, "Expression of the NG2 proteoglycan enhances the growth and metastatic properties of melanoma cells," Journal of Cellular Physiology, vol. 177, no. 2, pp. 299-312, 1998.

[188] J. Yang, M. A. Price, Y. L. Gui et al., "Melanoma proteoglycan modifies gene expression to stimulate tumor cell motility, growth, and epithelial-to-mesenchymal transition," Cancer Research, vol. 69, no. 19, pp. 7538-7547, 2009.

[189] J. Iida, K. L. Wilhelmson, J. Ng et al., "Cell surface chondroitin sulfate glycosaminoglycan in melanoma: role in the activation of pro-MMP-2 (pro-gelatinase A)," Biochemical Journal, vol. 403, no. 3, pp. 553-563, 2007.

[190] A. Müller, B. Homey, H. Soto et al., "Involvement of chemokine receptors in breast cancer metastasis," Nature, vol. 410, no. 6824, pp. 50-56, 2001. 
[191] R. S. Taichman, C. Cooper, E. T. Keller, K. J. Pienta, N. S. Taichman, and L. K. McCauley, "Use of the stromal cell-derived factor-1/CXCR4 pathway in prostate cancer metastasis to bone," Cancer Research, vol. 62, no. 6, pp. 1832-1837, 2002.

[192] T. Oonuma, M. Morimatsu, T. Nakagawa et al., "Role of CXCR4 and SDF-1 in mammary tumor metastasis in the cat," Journal of Veterinary Medical Science, vol. 65, no. 10, pp. 1069-1073, 2003.

[193] H. Tamamura, A. Hori, N. Kanzaki et al., "T140 analogs as CXCR4 antagonists identified as anti-metastatic agents in the treatment of breast cancer," FEBS Letters, vol. 550, no. 1-3, pp. 79-83, 2003.

[194] J. Libura, J. Drukala, M. Majka et al., “CXCR4-SDF-1 signaling is active in rhabdomyosarcoma cells and regulates locomotion, chemotaxis, and adhesion," Blood, vol. 100, no. 7, pp. 2597-2606, 2002.

[195] M. Kato, J. Kitayama, S. Kazama, and H. Nagawa, "Expression pattern of CXC chemokine receptor-4 is correlated with lymph node metastasis in human invasive ductal carcinoma," Breast Cancer Research, vol. 5, no. 5, pp. R144-R150, 2003.

[196] M. Kucia, R. Reca, K. Miekus et al., "Trafficking of normal stem cells and metastasis of cancer stem cells involve similar mechanisms: pivotal role of the SDF-1-CXCR4 axis," Stem Cells, vol. 23, no. 7, pp. 879-894, 2005.

[197] C. C. Yun, H. Sun, D. Wang et al., "LPA2 receptor mediates mitogenic signals in human colon cancer cells," American Journal of Physiology, vol. 289, no. 1, pp. C2-C11, 2005.

[198] G. W. M. Swart, "Activated leukocyte cell adhesion molecule (CD166/ALCAM): developmental and mechanistic aspects of cell clustering and cell migration," European Journal of Cell Biology, vol. 81, no. 6, pp. 313-321, 2002.

[199] D. G. Lee, J.-H. Lee, B. K. Choi et al., "H+-myo-inositol transporter SLC2A13 as a potential marker for cancer stem cells in an oral squamous cell carcinoma," Current Cancer Drug Targets, vol. 11, no. 8, pp. 966-975, 2011.

[200] E. Martín-Villar, F. G. Scholl, C. Gamallo et al., "Characterization of human PA2.26 antigen (T1 $\alpha$-2, podoplanin), a small membrane mucin induced in oral squamous cell carcinomas," International Journal of Cancer, vol. 113, no. 6, pp. 899-910, 2005.

[201] P. Yuan, S. Temam, A. El-Naggar et al., "Overexpression of podoplanin in oral cancer and its association with poor clinical outcome," Cancer, vol. 107, no. 3, pp. 563-569, 2006.

[202] M. Kreppel, M. Scheer, U. Drebber, L. Ritter, and J. E. Zöller, "Impact of podoplanin expression in oral squamous cell carcinoma: clinical and histopathologic correlations," Virchows Archiv, vol. 456, no. 5, pp. 473-482, 2010.

[203] J. P. Rodrigo, D. García-Carracedo, M. V. González, G. Mancebo, M. F. Fresno, and J. García-Pedrero, "Podoplanin expression in the development and progression of laryngeal squamous cell carcinomas," Molecular Cancer, vol. 9, article 48, 2010.

[204] G. F. Huber, F. R. Fritzsche, L. Züllig et al., "Podoplanin expression correlates with sentinel lymph node metastasis in early squamous cell carcinomas of the oral cavity and oropharynx," International Journal of Cancer, vol. 129, no. 6, pp. 1404-1409, 2011.

[205] A. Funayama, J. Cheng, S. Maruyama et al., "Enhanced expression of podoplanin in oral carcinomas in situ and squamous cell carcinomas," Pathobiology, vol. 78, no. 3, pp. 171-180, 2011.

[206] I. H. El-Sayed, "Nanotechnology in head and neck cancer: the race is on," Current Oncology Reports, vol. 12, no. 2, pp. 121-128, 2010 . 

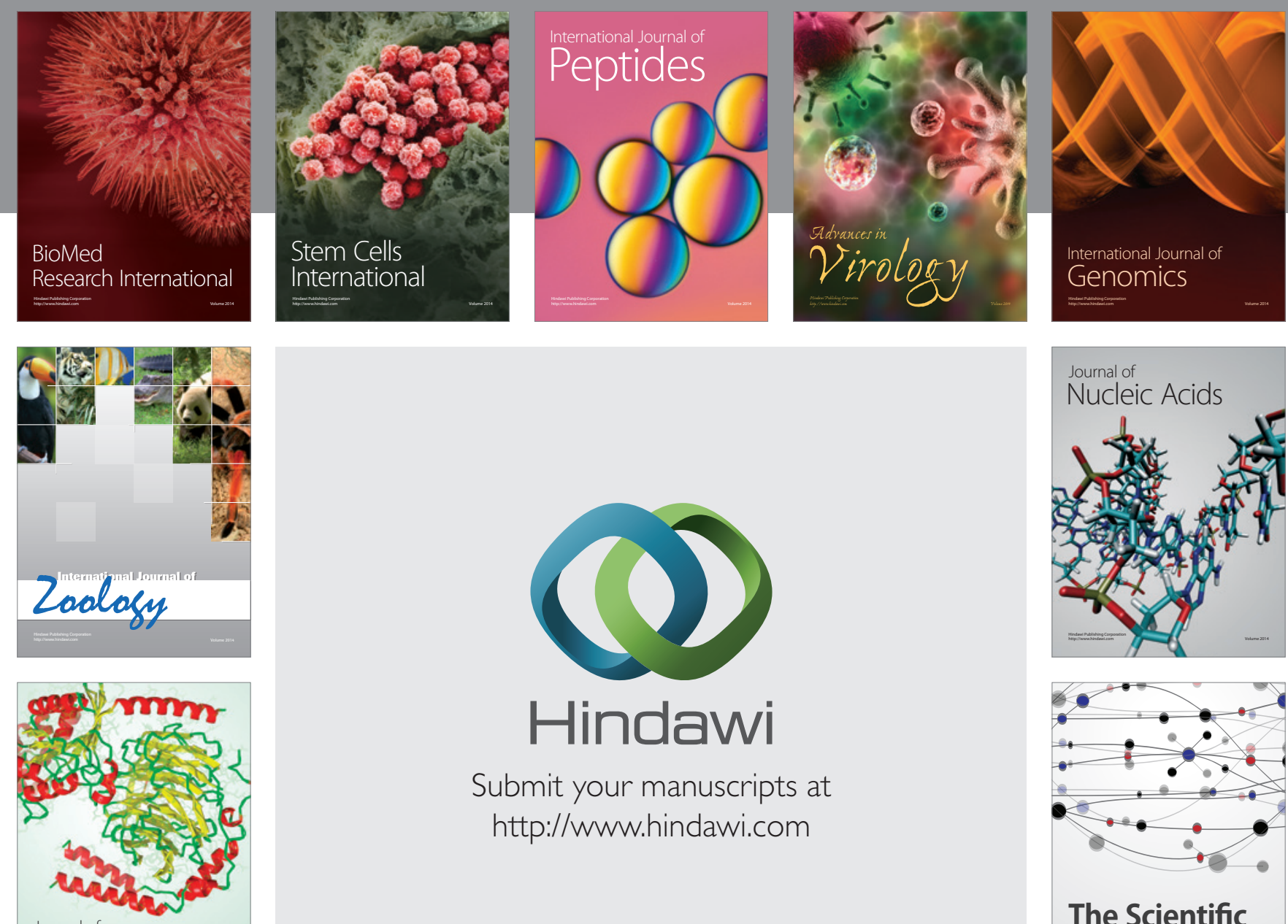

Submit your manuscripts at

http://www.hindawi.com

Journal of
Signal Transduction
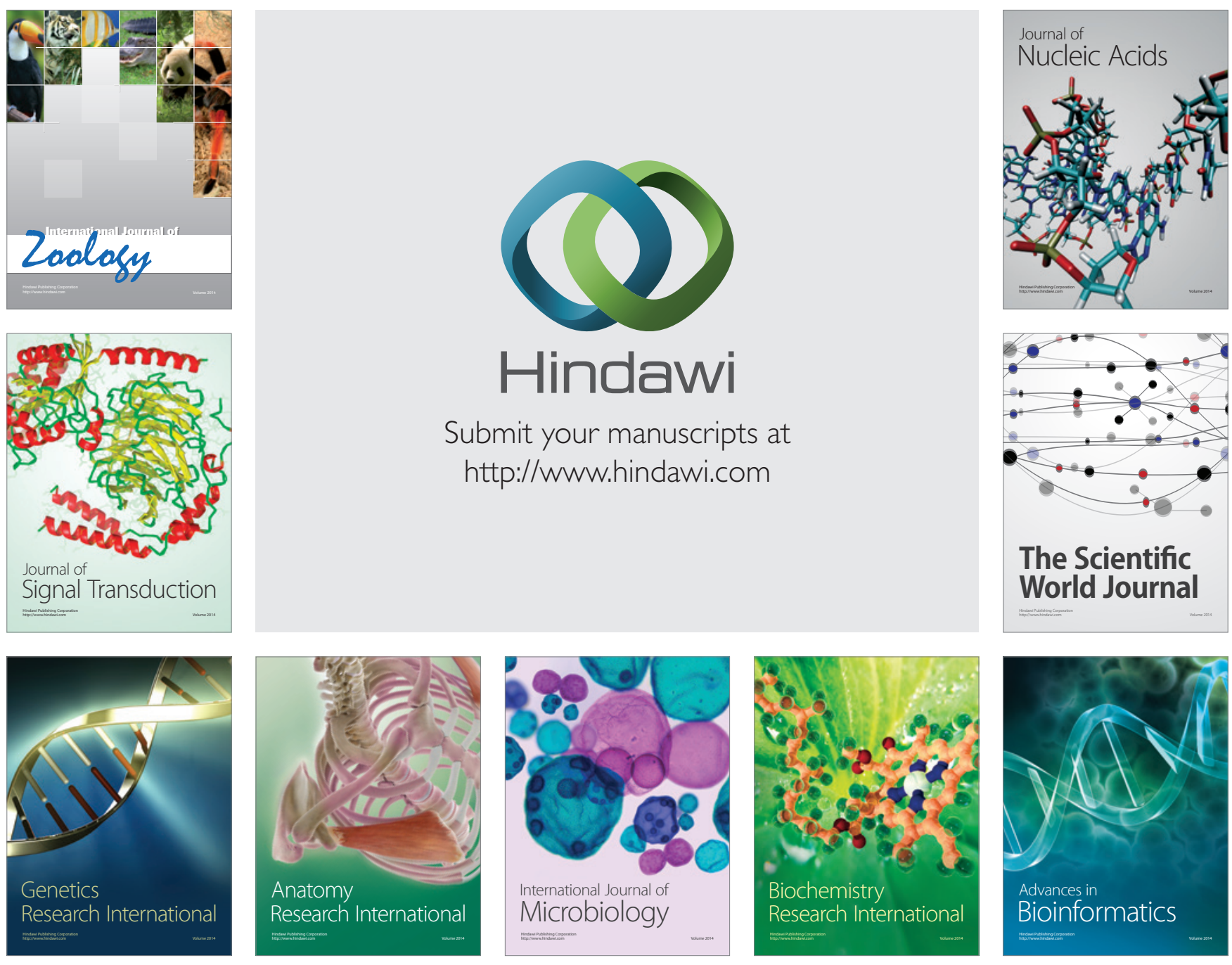

The Scientific World Journal
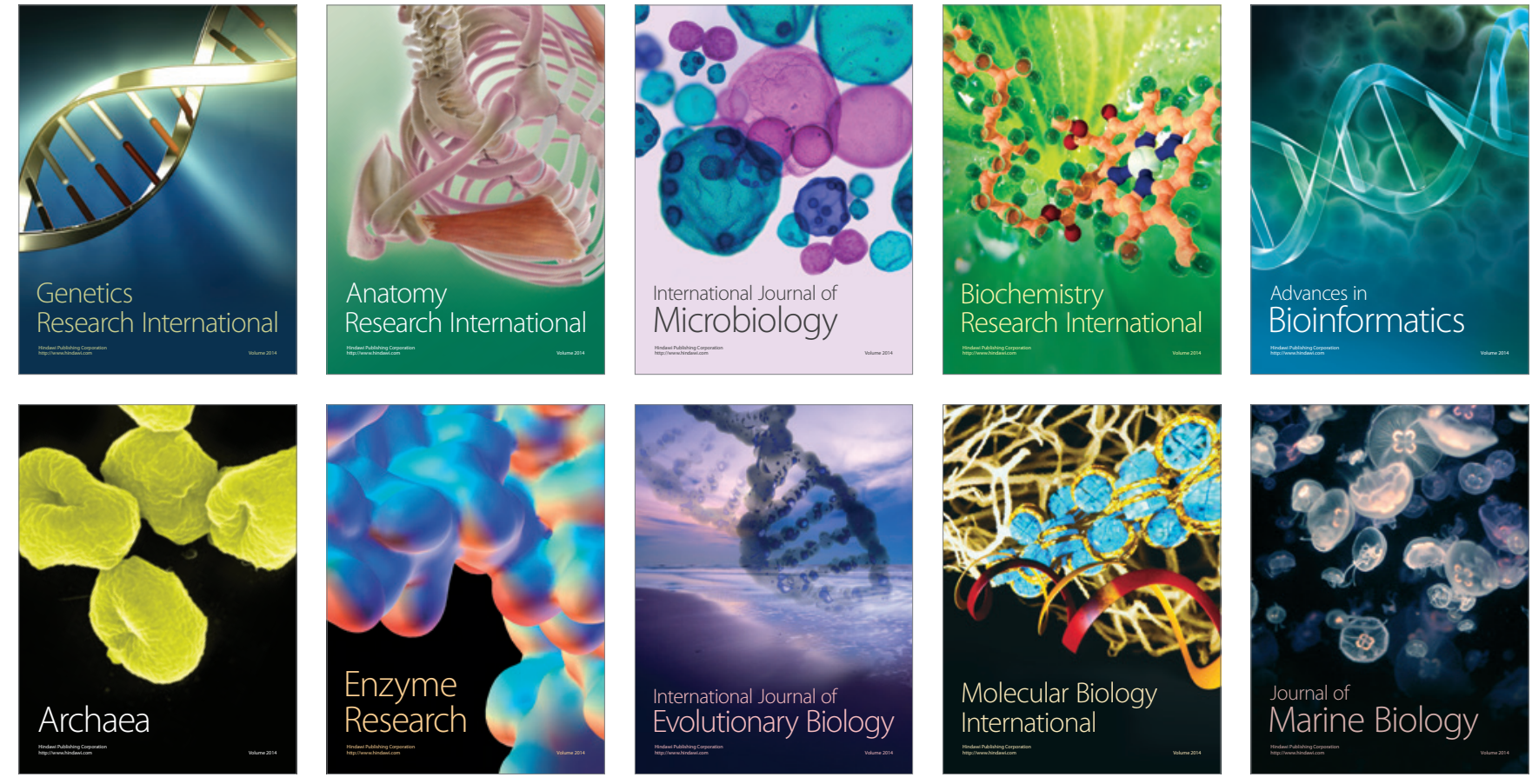